\title{
Editorial
}

\section{MANAGEMENT OF EDUCATION IN THE INFORMATION AGE}

\author{
Ian D. Selwood, Alex C.W. Fung and Christopher D. O’Mahony
}

Since the mid-1980s, computer assisted educational information systems have been developing in various parts of the world and the knowledge surrounding the development and implementation of these systems has been growing. In 1994, the first international working conference on Information Technology in Educational Management (ITEM) was held in Jerusalem. Two years later, a second working conference was held in Hong Kong and following this event, Working Group (WG) 3.7 of the International Federation for Information Processing (IFIP) was established. WG 3.7 focuses on promoting the effective and efficient use of IT in the management of educational institutions. Subsequently conferences have been held in Maine (USA), and Auckland (New Zealand) and Helsinki (Finland). The conferences have engendered a spirit of co-operation amongst people around the world resulting in the publication of five previous books; three special editions of academic journals; numerous academic papers; research funding obtained; and research projects completed. More detailed information about WG 3.7 can be found at - http://ifip-item.hkbu.edu.hk

The content of this book has 5 sections. The first four sections, consists of papers selected from the proceedings of the Fifth IFIP Working Conference of WG 3.7 on Information Technology in Educational Management, held between August 18 - 22, 2002 in Helsinki, Finland. All conference presentations were selected after peer review by an international panel. A further review then identified papers for publication in this book. Thus, the book is not a full conference proceedings, but a selection of papers that were selected for their quality, and capture the range and essence of the conference. The fifth section of the book consists of reports from the discussion groups that met throughout the conference. These reports

The original version of this chapter was revised: The copyright line was incorrect. This has been corrected. The Erratum to this chapter is available at DOI: 10.1007/978-0-387-35689-1_19 
represent a valuable addition to the subjects covered by the papers and cover key topics of current interest within the ITEM community. They report the deliberations, ideas and key issues that emerged.

\section{SECTION 1 - ICT FOR MANAGING STUDENT LEARNING}

The two papers in this section examine management issues relating to the use of ICT (Information and Communication Technology) in the classroom.

Leonard Newton's paper argues that problems of integrating ICT into the teaching and learning of other subjects have a managerial dimension that relates to the planning and implementation of lessons. Newton draws on experiences in science education and presents frameworks that offer a means of analysing the beneficial features of ICT in relation to teaching and learning goals and identifying the skills of classroom application required to achieve these.

Chris Thorn's paper examines the problems and challenges that teachers and school managers encounter, in the USA, when attempting to implement data-based decision-making reform efforts, specifically those decisions that influence teaching and learning in the classroom. Thorn argues that while large-scale assessment and accountability data are generally available these are limited to the operational needs of schools and districts for gauging the performance of educational systems. He contends that there are major differences between the evidence used for external accountability systems and the data needed for making instructional decisions on a daily basis in the classroom, and this data is lacking. Thorn further argues that educational organizations have little experience integrating complex data into their decision-making processes.

\section{SECTION 2 - ICT FOR MANAGING EDUCATIONAL INSTITUTIONS}

This section not only demonstrates the international nature of the conference, and this publication, with papers reporting on ITEM in Australia, Botswana, Canada, England, and Slovenia; but also the scope of ITEM with papers reporting on ITEM in schools, universities and central government.

At the two previous conferences of WG 3.7, the evaluation of the implementation of computerised school information systems (SISs) in Hong Kong and The Netherlands were presented. The paper written by Adrie 
Visscher, Phil Wild and Debbi Smith describes an evaluative study of the implementation of the School Information Management System (SIMS) which is used to support management and administration in the majority of English secondary schools. The large-scale survey carried out for this study showed that use of SIMS tends to be clerical, and that the use of SIMS to support school managers is still very limited. A range of problems is identified in the paper and these include the reliability of SIMS, user training (especially managers), user support, and the clarity of the innovation process. However, despite these problems users are in general positive on the effects of SIMS use. The paper concludes that wider and better SIMS use would be promoted by more carefully designed needs-based user training. (Training issues are further discussed in Section 3 of this book.)

Whilst England has a comparatively long history of the use of ITEM, Botswana has only recently started to implement this use of ICT, and the approach is very different. The paper by Coach Kereteletswe and Ian Selwood briefly describing Botswana and its education system before presenting a framework for analysing the implementation of ITEM in developing countries, and subsequently describes the first stages of ITEM implementation in Botswana. Botswana, like many developing countries, has an education system that has a highly centralised management structure, with very few management responsibilities devolved from central government. The approach to implementing ITEM commencing at the Ministry and then rolling out down the system is perhaps unique.

Following a review of the literature concerning the impact of ICT on the work of school principals in various countries, Margaret Haughey reports on her research from Canada, where in the jurisdiction she studied, the process of technology integration is only just beginning. However, she reports that the impact of ICT has already been felt in the principals' offices with principals required to be more knowledgeable about various computer applications, to correspond easily via e-mail, and to organize and retrieve information. Furthermore, she reports that principals are under increased pressure to ensure the quality of their schools, as the district has used the information provided by principals to identify poorly performing schools.

The paper by Arthur Tatnall and Allan Pitman further addresses the issue of accountability of schools. In their paper, they argue that even though the use of ITEM offers many advantages to schools it also serves a role in acting to control schools. The use of ITEM in schools in Victoria, Australia and Ontario, Canada is examined in the paper. The authors then argue that even in areas where management responsibilities are devolved to schools, from central education authorities, ITEM may actually play a significant role in tightening the coupling between schools and central education authorities. 
This they argue leads to greater standardisation and control over the way that schools perform their administrative functions.

Much of the previously published literature on ITEM has concentrated on the use of information systems in schools. The final two papers in this section, however, discuss the use of ITEM at University level. Nonetheless, a pertinent issue raised when examining ITEM use in higher education may well have a parallel in schools and vice versa. Chris Thorn's paper (see Section 1) raised the issue of access to appropriate student records, by teaching staff, so that data could be used for planning teaching and learning. The papers by Bill Davey and Arthur Tatnall, and Marko Bajec, Viljan Mahnič and Marjan Krisper both deal with this issue.

Following their concern that student records systems could, in many cases, easily provide much more useful teaching information than they currently do Bill Davey and Arthur Tatnall's paper reports on research into student records systems. The paper argues that academics, in their teaching role, should be regarded as significant stakeholders in student records systems, but notes that often their needs have not been considered. Research was initially undertaken in three universities in Australia but was followed by a larger international survey. The question of how well university administrative systems meet the needs of teaching, and what information university teachers might wish to obtain from such systems, but cannot obtain now, is also discussed. To determine the focus of a university student records system, and how well it relates to classroom teaching needs, a 'litmus test' was developed and trialled.

Marko Bajec, Viljan Mahnič and Marjan Krisper's paper describes how as part of the University of Ljubljana's Information Systems (IS) Strategy Plan their current student records IS was renovated using a technology which seemed to be very promising in developing integrated, user-centric IT solutions. The strategy plan had revealed many weaknesses and disadvantages with the university IS. One of these was the lack of the possibility to utilize e-business technology. The paper briefly describes the University of Ljubljana's IS Strategy Plan and discusses some characteristics of the portal technology that enabled wider, user-centric access of the student records IS.

\section{SECTION 3 - THE MANAGEMENT OF E- LEARNING}

In this section, the focus is once again, predominantly on the University sector. The four papers published here examine various aspects of the management of e-learning. Alex Fung and Jenilyn Ledesma describe how, 
at the Hong Kong Baptist University (HKBU), a Taskforce was set up to promote web based teaching and learning activities within the university community. Their paper reports some preliminary findings on the nature, approach and progress made by the Taskforce during its first phase of implementation of the WebCT - the current platform for the initiative. The paper sheds light on what academic staff at HKBU need to support their use of web based technologies for teaching and learning and highlights that the potential benefit of IT can be realized provided careful attention is paid to a range of factors.

The remaining two papers in this section deal with the development of elearning systems, and a central concern to all the authors is collaboration and how e-learning systems may address this concern. Based on a concern that Learning Management Systems (LMS) suffer from lack of flexibility in sharing and exchanging learning resources and learner data, Rima Abdallah, Abdelmalek Benzekri, Ali El Hajj and Ibrahim Moukarzel present in their paper a new Web Based Training/Education (WBT/E) Model based on the Learning Technology Systems Architecture (LTSA) standard and on the WBT Model of the Enhance Project. To illustrate the model, a scenario of collaborative learning is presented. WebCT was used as the distancelearning platform, RealNetworks family for manipulating synchronized multimedia courses integrated in WebCT, and Microsoft NetMeeting for providing audio/video/sharing of application among the collaborators.

In the paper by Mario Marrero, Celso Perdomo, Jorge Rodríguez and Antonio González, the authors argue that in the past the focus of much research concerned with the implementation of information technologies in organizations, was on the interaction between a human and a machine. However, they feel that this approach ignores the fact that many tasks in organizations necessarily have a collaborative aspect. In their paper Marrero et al. discuss groupware technologies and introduce an Internet-based tool, HTC, which is a collaborative and distributed application where an individual workspace can be created for each user, which can in turn, be shared partially or totally with other HTC users. The paper then describes the integration process of HTC in the University of Las Palmas de Gran Canaria and its use by students and academics.

\section{SECTION 4 - ICT TRAINING FOR EDUCATIONAL PROFESSIONALS}

Training to educationalists to use ICT effectively for administration management and, teaching and learning, has been a recurrent issue at previous ITEM and other conferences concerned with ICT in education. The 
following three papers again address this issue. The need for ongoing training is demonstrated in Christopher O'Mahony's paper. The papers presented by Javier Osorio and Maureen Lambert and Patrick Nolan both present models for the effective implementation of training programmes

Christopher O'Mahony's paper reports on a survey that investigated the use of ICT by academic and non-academic staff at an independent English secondary school. Three key areas were investigated: access to ICT inside and outside the school, the perceived and desired ICT ability of staff, and issues preventing increased use of ICT in teaching, learning and administration. The paper concludes that despite recognition that there is a growing obligation and desire to incorporate ICT elements into teaching and learning, including lesson preparation, teachers still report concerns with training and the amount of time available to improve their skills with ICT, and that there is a need for a well-defined programme for professional development.

Maureen Lambert and Patrick Nolan's paper asserts that ICT implementation in educational institutions has proved to be problematic with outcomes falling far below expectations. They suggest that a solution is a more holistic approach to professional development that takes into account the school-learning environment, including school culture, in an effort to develop educational practitioners as 'all-round' capable ICT-using professionals. They argue that professional development should be linked directly to the contexts where ICT may be used professionally and that development will be most effective by identifying and addressing two simultaneous pathways namely, learning and teaching, and administration and management. To this end, the paper proposes, develops and explains a model of professional development in ICT for teachers.

The objective of the paper by Javier Osorio is to develop a framework for evaluating the likelihood of success in the development of training courses for ITEM systems at managerial level. The paper argues that environmental factors can influence greatly the success of any training course. A review of the literature on contextual factors affecting the training process where variables such as ICT, management, organisational features and managers' profile are present, was undertaken from this review, a list of factors arose. The paper then puts forward and examines a systematic method to analyse the influence of such factors on the global attractiveness of the training process' environment. 


\section{SECTION 5 - REPORTS FROM DISCUSSION GROUPS}

The three papers in this Section of the book are reports from the three discussion groups that met at various times throughout the conference. The reports cover three key topics of current interest within the ITEM community - The Management of e-Learning, Management Systems in the Classroom and Core Competences for ITEM.

The discussion group on the Management of e-Learning was chaired by Alex Fung and explored and addressed several areas regarding the management of e-Learning. Building on the discussion, six issues were identified by the end of the conference. These 6 issues - Definition of eLearning; Visions of e-Learning [Dreams for the new education system]; How to get there with the support of technology; Changes needed to support e-Learning; Different roles to make e-Learning operational; and other issues and points to ponder provide the structure for this discussion paper.

The discussion group chaired by Adrie Visscher and Leonard Newton considered Management Systems in the Classroom prospects for the future. The paper examines some issues related to the use of Management Information Systems (MIS) in classroom contexts and considers some possible future needs of teachers that may present challenges to the designers of the next generation of MIS tools. The key issue that group felt needed addressing - is how MIS users might more effectively exploit their potential in individual classrooms: particularly in ways that support both the broad standards agenda and, more importantly, the achievements of individual learners.

The third discussion group chaired by Ian Selwood had the mandate to explore the Core Competences required for ITEM. The concern here arose from the fact that it was perceived that attempts to introduce new technologies into educational institutions often lacked coherent and effective training programmes. Having reviewed what literature exists on this topic the discussion group developed a competency based model or framework, which should enable educational institutions to plan their ITEM training and achieve an ITEM-competent staff. The report from the discussion group therefore reviews the literature, presents what the group considers to be a unique and important model, and discusses the advantages of the approach suggested in the model, prior to making the point that further work is needed to elaborate the model. 